\title{
RANCANG BANGUN GAME EDUKASI "MATCHING AKSARA LAMPUNG” BERBASIS SMARTPHONE ANDROID
}

\author{
Agus Mulyanto $^{1}$, Apriyadi $^{2}$, Purwono Prasetyawan ${ }^{3}$ \\ Program Studi Informatika \\ Fakultas Teknik\& IlmuKomputer \\ Universitas Teknokrat Indonesia
}

Jl. Zainal Abidin Pagar Alam No 9 - 11 Bandarlampung Lampung Indonesia

'apriyadisuccess@gmail.com, ${ }^{2}$ agus.mulyanto@teknokrat.ac.id, ${ }^{3}$ purwono.prasetyawan@teknokrat.ac.id

\begin{abstract}
Abstrak - Aksara Lampung merupakan bentuk tulisan yang memiliki hubungan dengan aksara Pallawa dari India Selatan.Saat ini minat dan keinginan masyarakat terutama di kalangan anakanak dalam mempelajari Aksara Lampung semakin menurun.Dalam perkembangan teknologi yang ada saat ini, diperlukan sebuah media pendukung pembelajaran yang interaktif dan menghibur dengan tetap mengikuti perkembangan teknologi yang ada. Android merupakan sistem operasi berbasis open source membebaskan pengguna untuk mengembangkan aplikasi.Tujuan dari penulisan ini adalah membuat game edukasi. GameEdukasi Matching merupakan game mencocokkan gambar dengan menggunakan pengacakan gambar terlebih dahulu. Pengacakan gambar pada game menggunakan algoritma fisher yates.Pengembangan aplikasi game matching Aksara Lampung menggunakan software Construct 2 yang akan dijalankan pada platform Android. Metode pengujian kualitas pada game menggunakan iso 9126. Hasil pengujian kualitas yang diperoleh aspek functionality $100 \%$ valid, aspek portability dengan OS Android versi Lolipop, Marshmello, dan Nougat $100 \%$ valid, aspek usability diperoleh nilai $\mathbf{9 5 , 2 2} \%$, dan aspek efficiency menunjukan tidak adanya kekurangan memory dan penggunaan CPU oleh aplikasi sebesar $44 \%$.
\end{abstract}

Kata kunci — Aksara Lampung, Matching Game, Android, Fisher Yates

\section{PENDAHULUAN}

\section{A. Latar Belakang}

Provinsi Lampung merupakan salah satu daerah yang memiliki bahasa dan aksara daerah. Aksara Lampung atau Had Lampung yang biasa disebut dengan istilah $\mathrm{KaGaNga}$ ditulis dan dibaca dari kiri ke kanan dengan Huruf Induk berjumlah 20 huruf [1].Pemerintah Provinsi Lampung mewajibkan seluruh sekolah dasar dan menengah untuk memberikan mata pelajaran bahasa Lampung kepada siswanya termasuk pengenalan Aksara Lampung.Pembelajaran aksara lampung di sekolah dasar merupakan sarana pelestarian dari budaya lampung.Namun, pembelajaran Aksara Lampung di sekolah dasar untuk era modern ini minat siswa rendah terhadap pelajaran bahasa lampung.

Dalam perkembangan teknologi yang ada saat ini, diiringi juga dengan berkembangnya cara edukasi, salah satunya dengan bermain game pada smartphone. Menstimulasi otak dengan bermain game adalah cara paling menyenangkan, selain itu juga dapat menjaga performa daya ingat agar tetap bagus. Bermain game adalah salah satu cara untuk menstimulasi otak.

Game edukasi match merupakan game yang mencocokkan gambar dengan menggunakan pengacakan gambar terlebih dahulu. Urutan penempatan gambar akan berbeda pada setiap levelnya,sehingga penempatan gambar bersifat dinamis. Game ini bertujuan sebagai media hiburan dan pembelajaran selain itu mengasah memori pengguna

Teknologi dapat dimanfaatkan untuk berbagai keperluan, salah satunya media pembelajaran. Dalam hal ini bisa memanfaatkan suatu perangkat seperti smartphone atau tablet $P C$ untuk menyampaikan suatu materi agar pembelajaran dalam bentuk game edukasi. Menurut[2] menyatakan bahwa hasil analisis yang telah dilakukan, memperlihatkan bahwa kenaikan penggunaan smartphone untuk membunuh rasa malas belajar dapat meningkatkan prestasi belajar. Dengan kata lain, ketika masyarakat sedang merasa bosan atau jenuh mereka memanfaatkan smartphone sebagai media untuk refreshing.

Sistem operasi pada smartphone yang paling banyak digunakan saat iniadalah sistem operasi Android menurut Survey APJII November 2016.Android merupakan sistem operasi yang bersifat terbuka.Android bisa digunakan oleh setiap orang yang ingin menggunakannya pada perangkat mereka. Android menyediakan platform terbuka bagi para pengembang untuk menciptakan aplikasi mereka sendiri yang akan digunakan untuk bermacam piranti gerak [3].

Menurut[4] menyatakan bahwa Game edukasi adalah game yang dirancang untuk pendidikan dengan cara menyisipkan materi-materi pembelajaran tertentu pada permainan sehingga user atau pemain tidak tertekan dengan belajar terlalu serius.

Dalam penelitian terkait algoritma Fisher-Yates digunakan untuk pengacakan.Algoritma Fisher-Yates saat ini telah banyak digunakan dalam proses 
pengembangan suatu penelitian, metode pengacakan ini termasuk metode pengacakan yang baik pada pengembangan suatu aplikasi. Implementasi algoritma tersebut di dalam aplikasi ini didasari juga pada masalah yang terjadi yaitu kurangnya minat anakanak untuk mengenal huruf Aksara Lampung.

Mengingat betapa pentingnya pengenalan Aksara

Page | 37 Lampung bagi siswa. Maka dibutuhkan suatu aplikasi pengenalan huruf Aksara Lampung bagi siswa yang tidak menjemukan yakni, dengan membuat game yang bersifat pembelajaran Aksara Lampung.

Berdasarkan uraian masalah diatas, maka penulis mengusulkan penenelitian dengan judul "Rancang Bangun Game Edukasi "Aksara Lampung Matching" berbasis Smartphone Android" yang diharapkan dapat membantu dan meningkatkan minat anak Sekolah Dasar untuk mempelajari Aksara Lampung secara lebih interaktif dan menghibur.

\section{B. Rumusan Masalah}

Berdasarkan latar belakang masalah di atas dapat dirumuskan masalah sebagai berikut:

1. Bagaimana merancang dan membuat Aplikasi game edukasi yang dapat berjalan pada smartphone Android?

2. Bagaimana membangun sebuah game edukasi yang dapat digunakan untuk mempelajari Aksara Lampung?

3. Bagaimana cara menarik minat anak Sekolah Dasar untuk mengenal dan mempelajari Aksara Lampung?

\section{Batasan Masalah}

Berikut batasan masalah dalam penelitian ini agar ruang lingkup masalah tidak meluas yaitu:

1. Aplikasi yang dibangun lebih ditujukan untuk anak Sekolah Dasar.

2. Aplikasi yang akan dibangun merupakan game edukasi dengan tampilan dua dimensi (2D).

3. Aplikasi yang akan dibangun menggunakan game engine Construct 2.

4. Aplikasi yang akan dibangun tidak menterjemahkan kata atau bahasa lampung.

5. Aplikasi yang akan dibangun hanya menggunakan induk huruf dan anak huruf Aksara Lampung.

6. Pengujian aplikasi hanya menggunakan 4 karakteristik pada ISO 9126, functionality, usability, portabilitidan efficiency.

7. Tahapan pengembangan aplikasi multimedia tidak meliputi distribution.

\section{Tujuan Penelitian}

Adapun tujuan yang menjadi tujuan penelitian ini adalah:

1. Membangun sebuah game edukasi yang dapat digunakan untuk mengenalkan dan mempelajari Aksara Lampung yang lebih interaktif dan menghibur.

2. Meningkatkan minat anak Sekolah Dasar untuk mengenal dan mempelajari Aksara Lampung.

\section{E. Manfaat Penelitian}

Adapun manfaat yang di harapkan dari penelitian ini adalah:

1. Sebagai media hiburan serta pembelajaran bagi anak sekolah dasar untuk mengenal Aksara Lampung.

2. Dapat mengembangkan kemampuan penulis dalam melakukan penelitian dan pembuatan aplikasi mobile berbasis Android.

3. Dapat menjadi dalah satu media untuk melestarikan warisan budaya lampung.

\section{LANDASANTEORI}

\section{A. Aksara Lampung}

Aksara Lampung yang disebut dengan Had Lampung adalah bentuk tulisan yang memiliki hubungan dengan aksara Pallawa dari India Selatan. Macam tulisannya fonetik berjenis suku kata yang merupakan huruf hidup seperti dalam Huruf Arab dengan menggunakan tanda-tanda fathah di baris atas dan tanda tandakasrah di baris bawah tapi tidak menggunakan tanda dammah di baris depan melainkan menggunakan tanda di belakang, masingmasing tanda mempunyainama tersendiri [5]. Terdapat 20 induk huruf dalam penulisan aksara lampung, yaitu: ka, ganga, pa, ba, ma, ta, da, na, ca, ja, nya, ya, a, la, la, ra, ra, sa, wa, ha, gha[6]bentuk induk huruf dapat dilihat pada Gambar 1.

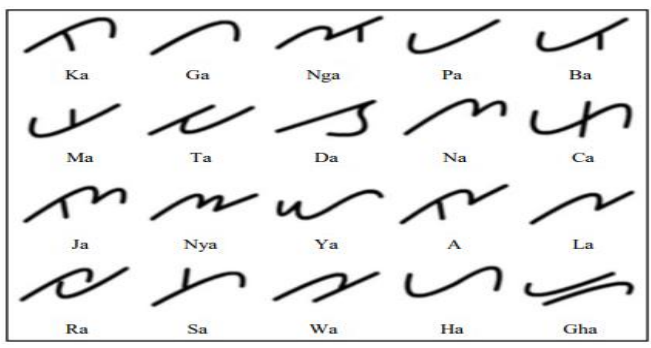

Gbr. 1 Induk Huruf Aksara Lampung

Menurut [6] dalam aksara lampung selain induk huruf terdapat juga 12 anak huruf yang terletak di atas, samping kanan atau depan dan bawah induk huruf.

1) Anak huruf yang terletak di atas induk huruf

TABEL 1

ANAK HURUF YANG TERLETAK DI ATAS INDUK HURUF

\begin{tabular}{|c|c|c|}
\hline Nama & Bunyi & Simbol \\
\hline Ulan & $i$ & \\
\hline Ulan & $e$ & \\
\hline Bicek & $e$ & \\
\hline Rejunjung & $r$ & \\
\hline Tekelubang & $n g$ & \\
\hline Datas & $n$ & \\
\hline
\end{tabular}

2) Anak huruf yang terletak di depan induk huruf 
TABEL 2

ANAK HURUF YANG TERLETAK DI DEPAN INDUK HURUF

\begin{tabular}{|c|c|c|}
\hline Nama & Bunyi & Simbol \\
\hline Tekelingai & $A i$ & $\ldots . . . . . . .$. \\
\hline Keleniah & $A h$ & $\ldots . . . .$. \\
\hline Nengen & - & ......... \\
\hline
\end{tabular}

3) Anak huruf yang terletak di bawah induk huruf.

TABEL 3

ANAK HURUF YANG TERLETAK DI BAWAH INDUK HURUF

\begin{tabular}{|c|c|c|}
\hline Nama & Bunyi & Simbol \\
\hline Bitan & $o$ & $\mathbf{I}$ \\
\hline Bitan & $u$ & - \\
\hline Tekelungau & $a u$ & $\mathbf{U}$ \\
\hline
\end{tabular}

\section{B. Game}

Dalam [7], Yudhanto menyatakan bahwa, Game adalah permainan yang menggunakan media elektronik, merupakan sebuah hiburan berbentuk multimedia yang dibuat semenarik mungkin agar pemain bisa mendapatkan sesuatu sehingga adanya kepuasaan batin.

\section{Game Edukasi}

Game edukasi atau biasa juga disebut sebagai edutainment, adalah bagian dari permainan komputer pendidikan yang mudah dikenali dengan struktur reward atau penghargaan yang jelas dalam permainan terpisah dari pengalaman pendidikan [8].

\section{Pembelajaran Interaktif dan Menghibur}

Pembelajaran Interaktif cocok untuk diterapkan pada game edukasi yang bersifat individual maupun kelompok. Proses belajar secara interaktif maka akan terjadi komunikasi dua arah, dimana pertanyaan muncul secara acak pada layar komputer atau handphonedan siswa menjawab pertanyaan tersebut.

Hampir semua permainan bertujuan untuk menghibur, begitu juga dengan permainan dalam pembelajaran, selain itu untuk menyenangkan siswa juga berupaya untuk menumbuhkan motivasi [9].

\section{E. Construct 2}

Construct 2 merupakan tools untuk membuat permainan berbasis HTML 5, yang memungkinkan untuk membuat dan mengembangkan permainan dua dimensi yang mampu dijalankan pada berbagai platform berbeda [10].

\section{F. Algoritma Fisher Yates}

Menurut [11], Fisher Yates merupakan salah satu metode pengacakan yang baik digunakan dalam pengembangan suatu aplikasi.Fisher yates(diambil dari nama Ronald Fisher dan Frank Yates) atau juga dikenal dengan nama Knuth shuffle (diambil dari nama Donald Knuth), adalah sebuah algoritma untuk menghasilkan suatu permutasi acak dari suatu himpunan terhingga, dengan kata lain untuk mengacak suatu himpunan tersebut. Jika diimplementasikan dengan benar, maka hasil dari algoritma ini tidak akan berat sebelah, sehingga setiap permutasi memiliki kemungkinan yang sama.

\section{G. Metode Pengacakan Fisher Yates}

Metode Pengacakan Fisher-Yates adalah sebuah metode untuk menghasilkan suatu permutasi acak dari suatu himpunan terhingga, dengan kata lain untuk mengacak suatu himpunan tersebut.

Misalkan dalam permainan kartu bridge ada 10 kartu yang diacak, maka array-nya adalah urutan Kartu $=[0,1,2,3,4,5,6,7,8$, 9]. Array tersebut dimasukkan kedalam prosedur pengacakan dimana proses pengacakan terjadi, kemudian didapat panjang array yang kemudian dimasukkan ke dalam variabel $\mathrm{m}(\mathrm{m}=10)$.

Langkah-langkah pengacakan soal dengan Metode Pengacakan Fisher-Yates adalah sebagai berikut :

1. Ambil satu elemen secara acak dari elemen yang tersisa. Pengambilan elemen acak adalah berdasarkan elemen yang tersisa.Misalkan jika m $=10$, maka elemen acak yang boleh diambil adalah 10 (array[0...9]).

2. Tukar dengan elemen saat ini. Penukaran dilakukan dengan memasukkan elemen saat ini ke dalam suatu variabel baru bernama t. Elemen saat ini (array[m]) diisi nilai dari elemen acak tadi (array[i]) dan elemen acak (array[i]) diisi nilai dari variabel $t$.

3. Ulangi selama masih ada elemen yang tersisa

Tahap ketiga dilakukan pengulangan sebanyak 10 kali untuk mengacak urutansoal tersebut,seperti ditunjukkan pada Tabel 4.

TABEL 4

PERHITUNGAN METODE FISHER YATES

\begin{tabular}{|r|c|c|c|r|r|}
\hline $\mathbf{M}$ & $\mathbf{i}$ & array[i] & t array[m] & array yang sudah diacak & isi array setelah ditukar \\
\hline 10 & 6 & 6 & 9 & 6 & $0,1,2,3,4,5,9,7,8,6$ \\
\hline 9 & 0 & 0 & 8 & 0,6 & $8,1,2,3,4,5,9,7,0,6$ \\
\hline 8 & 1 & 1 & 7 & $1,0,6$ & $8,7,2,3,4,5,9,1,0,6$ \\
\hline 7 & 2 & 2 & 9 & $2,1,0,6$ & $8,7,9,3,4,5,2,1,0,6$ \\
\hline 6 & 2 & 9 & 5 & $9,2,1,0,6$ & $8,7,5,3,4,9,2,1,0,6$ \\
\hline 5 & 1 & 7 & 4 & $7,9,2,1,0,6$ & $8,4,5,3,7,9,2,1,0,6$ \\
\hline 4 & 1 & 4 & 3 & $4,7,9,2,1,0,6$ & $8,3,5,4,7,9,2,1,0,6$ \\
\hline 3 & 1 & 3 & 5 & $3,4,7,9,2,1,0,6$ & $8,5,3,4,7,9,2,1,0,6$ \\
\hline 2 & 1 & 5 & 5 & $5,3,4,7,9,2,1,0,6$ & $8,5,3,4,7,9,2,1,0,6$ \\
\hline 1 & 0 & 8 & 8 & $8,5,3,4,7,9,2,1,0,6$ & $8,5,3,4,7,9,2,1,0,6$ \\
\hline
\end{tabular}

Hasil yang didapatkan adalah $8553 \quad 4 \quad 7 \quad 92210$ 6.Kolom $m$ menunjukkan index elemen saat ini.Kolom imenunjukkan index dari elemen yang ditukar, nilai i tersebut diambil secara acak dari range yang diperbolehkan $(m)$. Kolom array $[i]$ menunjukan nilai yang terdapat pada array ke- $i$. Kolom $t$ menunjukan nilai yang terdapat pada array ke- $m$ (elemen saat ini). Array yang sudah fix menunjukan 
array yang sudah tidak boleh ditukar kembali nilainya, jumlahnya bertambah seiring bertambahnya iterasi. Kemudian kolom array yang sudah diswap menunjukan isi array setelah elemennya ditukar atau swap ada setiap iterasi.

Page | 39

\section{PEMBAHASAN DAN IMPLEMENTASI}

A. Pengumpula Data

Penyusunan proposal penelitian ini tentu membutuhkan berbagai keterangan-keterangan lengkap. Peneliti mengumpulkan data-data tersebut dengan berbagai metode, yaitu:

1. Tinjauan Pustaka (LiteraturStudy)

2. Wawancara (Interview)

3. Kuesioner (Quesioner)

\section{B. Analisis Masalah}

Menyatakan bahwa Induk huruf dalam penulisan Aksara Lampung, yaitu: ka, ganga, pa, ba, ma, ta, da, na, ca, ja, nya, ya, a, la, la, ra, ra, sa, wa, ha, gha[6]. Dalam Aksara Lampung selain induk huruf terdapat juga 12 anak huruf yang terletak di atas, samping kanan atau depan dan bawah induk huruf [6].

Dalam Buku Pelajaran Bahasa Lampung menjelaskan metode yang digunakan untuk mengajarkan Aksara Lampung yaitu dengan cara menulis dan membaca Aksara Lampung [12].

Dalam mempelajari Aksara Lampung terdapat beberapa metode yaitu:

1. Menulis

2. Membaca

3. Mengucapkan

4. Mendengarkan

Berdasarkan metode pembelajaran Aksara Lampung yang ada, maka penulis menyimpulkan konsep game edukasi matching Aksara Lampung dalam penelitian ini menggunakan metode belajar dengan interaksi secara langsung menggunakan smartphone sebagai media bantu untuk mengenal Aksara Lampung yaitu:

1. Membaca bentuk induk huruf Aksara Lampung, dalam game ini terdapat informasi untuk mengenal bentuk induk huruf Aksara Lampung yang dikonsep dengan dibuatnya gamematching Aksara Lampung. Pengguna game ini dapat membaca atau melihat bentuk-bentuk induk huruf dan anak huruf di dalam menu petunjuk dalam game matching Aksara Lampung.

2. Mengucapkan, dalam game ini terdapat informasi bagaimana cara pengucapan induk huruf dan anak huruf Aksara Lampung. Sehingga pengguna game ini dapat mengikuti mengucapkan suara induk huruf dan anak huruf Aksara Lampung.

3. Mendengarkan suara Aksara Lampung, dalam game ini terdapat suara induk huruf Aksara Lampung. Terdapat pengenalan Aksara Lampung pada menu petunjuk Setiap pemain berhasil klik gambar aksara, game akan mengeluarkan suara sesuai huruf atau anak huruf Aksara Lampung. Sehingga dalam hal ini pengguna game dapat mendengarkan bagaimana pengucapan induk huruf maupun anak huruf Aksara Lampung.

Gameplay dari game Matching Aksara Lampung yaitu pemain diharuskan mencocokkan 2 kotak Aksara Lampung yang sama dalam kondisi kotak tertutup. Pemain cukup menyentuh (touch) pada layar smartphone Android untuk mencocokan 2 buah huruf Aksara Lampung yang sama dengan waktu yang telah ditentukan pada game ini, hingga tidak ada kotak Aksara Lampung yang tersisa. Pada game ini terdapat 3 level yaitu mudah, sedang dan sulit. Masing-masing level terdapat 5 tingkatan dengan jumlah kotak dan waktu yang bebeda di setiap tingkatannya. Jika pemain telah berhasil mencocokan semua kotak maka mendapat score +20 . Level game dapat dilihat pada Tabel 5.

TABEL 5

\section{LEVEL GAME}

\begin{tabular}{|c|c|c|c|c|c|}
\hline Mudah & Waktu & Sedang & Waktu & Sulit & Waktu \\
\hline 4 Kotak & 20 detik & 16 Kotak & 140 detik & 28 Kotak & 260 detik \\
\hline 6 Kotak & 40 detik & 18 Kotak & 160 detik & 30 Kotak & 280 detik \\
\hline 8 Kotak & 60 detik & 20 Kotak & 180 detik & 32 Kotak & 300 detik \\
\hline 10 Kotak & 80 detik & 22 Kotak & 200 detik & 34 Kotak & 320 detik \\
\hline 14 Kotak & 120 detik & 26 Kotak & 240 detik & 40 Kotak & 360 detik \\
\hline
\end{tabular}

\section{Flowchart Diagram}

Adapun flowchart diagram untuk merancang sistem tentang game edukasi matching aksara lampung, seperti ditunjukkan pada Gambar 2.

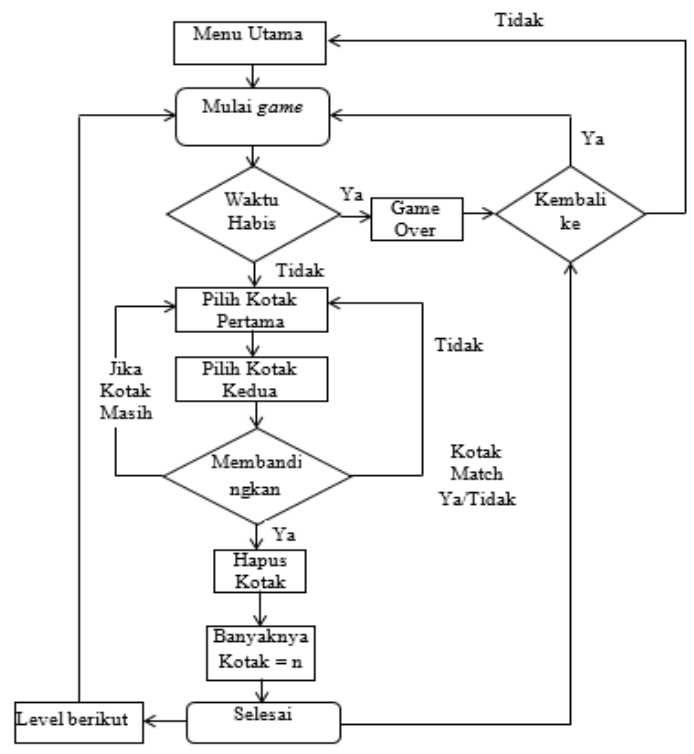

Gbr. 2 Flowchart Diagram

\section{1) Tampilan Menu Utama}

Form tampilan menu utama ini merupakan jendela bagi pemakai untuk memilih beberapa menu untuk mengoperasikan aplikasigame edukasi matching aksara lampung. Pilihan menu yang bisa 
dipilih oleh user terdiri dari mulai, petunjuk, tentang dan on/off suara, seperti ditunjukkan pada Gambar 3.

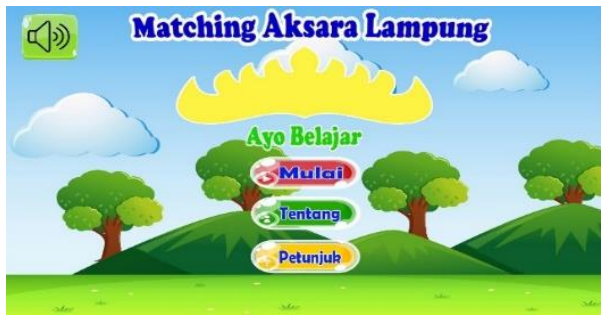

Gbr. 3 Tampilan Menu Utama

\section{2) Tampilan Level Game}

Tampilan menu pemilihan level memikibuttonlevel mudah, sedang dan sulit, jika level mudah di selesaikan maka akan lanjut level selanjutnya, seperti ditunjukkan pada Gambar 4.

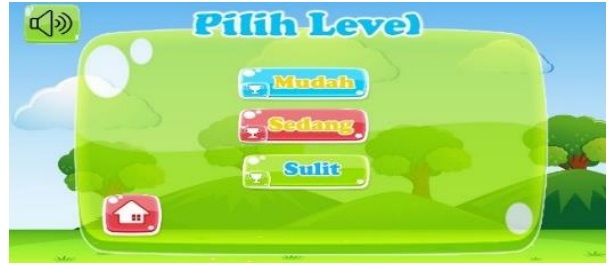

Gbr. 4 Tampilan Level

\section{4) TampilanPermainan}

Pada tampilan permainan terdapat tombol suara, info waktu, scoredan match, seperti ditunjukkan pada Gambar 5.

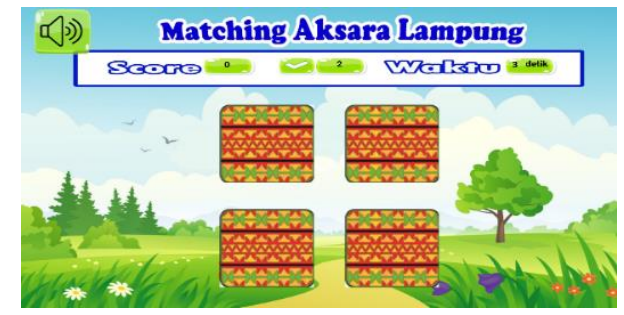

Gbr. 5 Halaman Permainan

4) TampilanGame Over

Halaman Game Over terdapat button home dan restart yang berguna untuk untuk mengulang kembali permainan, seperti ditunjukkan pada Gambar 6.

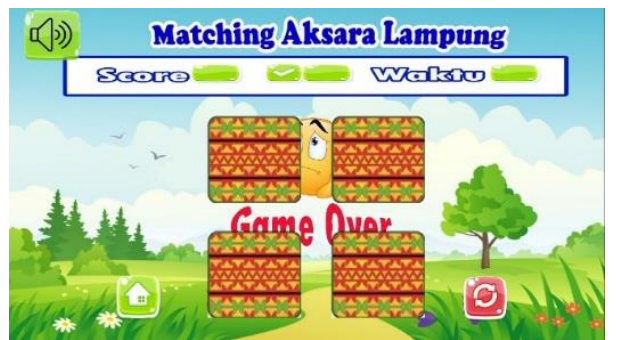

Gbr. 6 Game Over

\section{5) Halaman Tentang}

Halaman tentang terdapat informasi tentang aplikasi game seperti pembuat game, assets game, seperti ditunjukkan pada Gambar 7.

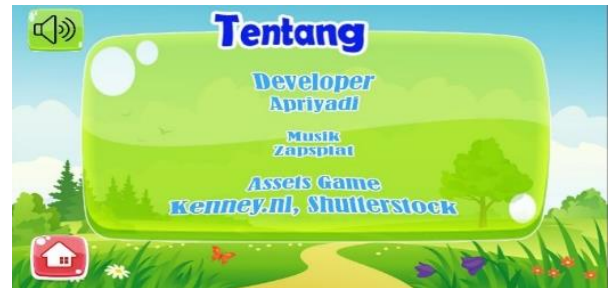

Gbr. 7 Halaman Tentang Aplikasi

\section{5) Pengujian}

Sebelum aplikasi ini disebarkan kepada pengguna maka aplikasi harus bebas dari beberapa kesalahan kesalahan.Oleh karena itu, aplikasi harus diuji terlebih dahulu oleh pembuat agar dapat menemukan kesalahan - kesalahan yang terjadi. Dalam penelitian ini menggunakan pengujian ISO 9126 yang meliputi 4 aspek yaitu ussability, functionality, portability dan efficiency. Berikut penjelasannya:

\section{7) PengujianUssability}

Pengujian aspek usability dilakukan terhadap siswa Sekolah Dasar kelas 2 SDN 1 Tanjung Agung dan SDN 1 Tanjung Raya Bandarlampung. Ada 60 responden yang menilai aplikasi game ini , responden mencoba aplikasi game edukasi matching Aksara Lampung pada device yang sudah disediakan kemudian responden mengisi kuisioner tersebut 15 pernyataan yang didalamnya terdapat 4 sub aspek yaitu, operability,learnability, understanabilitydan attractiveness dengan menggunakan skala $\mathrm{SS}=5, \mathrm{~S}=$ $4, \mathrm{~N}=3, \mathrm{TS}=2$, STS $=1$. Berikut data hasil pengujian aspek usability, seperti ditunjukkan pada Tabel 6.

TABEL 6

PENGUJIAN ASPEK USSABILITY

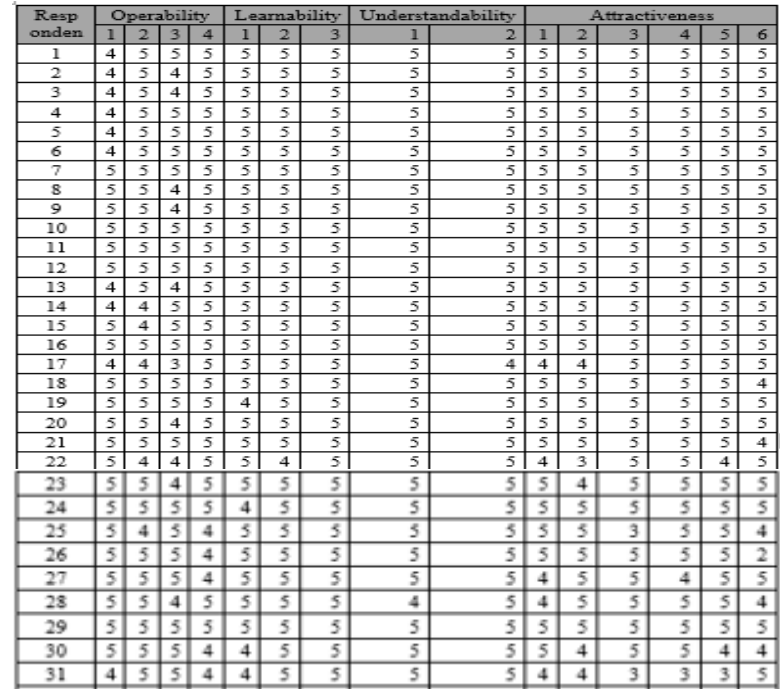




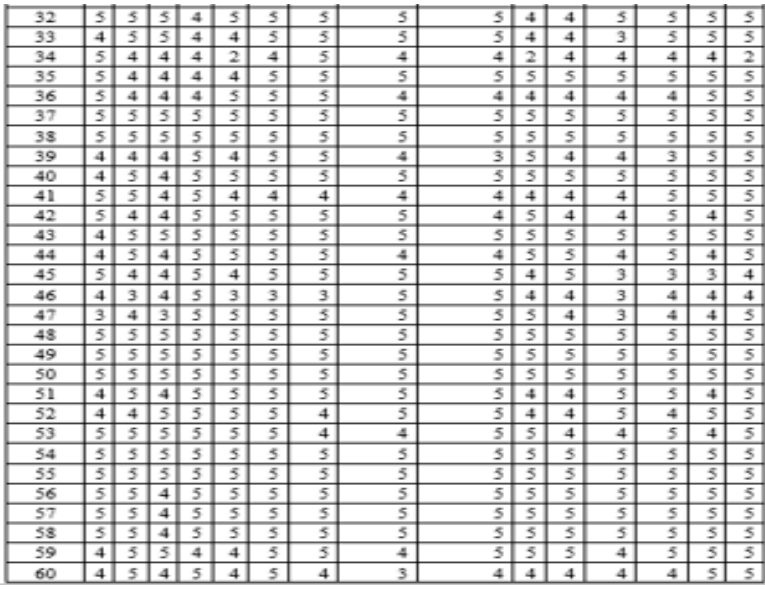

Berdasarkan data pengujian aspek ussability didapatkan nilai persentase, seperti ditunjukkan pada Tabel 7.

TABEL 7

PERSENTASE PENGUJIAN ASPEK USSABILITY

\begin{tabular}{|c|l|c|c|}
\hline No & \multicolumn{1}{|c|}{ Aspek } & Persentase & \multicolumn{1}{c|}{$\begin{array}{c}\text { Tingkat } \\
\text { Kelayakan }\end{array}$} \\
\hline 1 & Operability & $94 \%$ & Sangat Layak \\
\hline 2 & Learnability & $97 \%$ & Sangat Layak \\
\hline 3 & Understandability & $97 \%$ & Sangat Layak \\
\hline 4 & Attractiveness & $95 \%$ & Sangat Layak \\
\hline
\end{tabular}

Hasil pengolahan data uji usability menyatakan bahwa perangkat lunak memiliki nilai operability $94 \%$, learnability $97 \%$, understandability $97 \%$ dan attractiveness 95\%.Selanjutnya dilakukan perhitungan persentase untuk pengujian aspek usability secara keseluruhan dari data hasil pengujian menggunakan rumus:

$$
\begin{aligned}
& \text { Persentase Usability = } \\
& \frac{\text { total skor hasil pengujian }}{\text { skor tertinggi }} \times 100 \% \\
& \quad \frac{4285}{4500} \times 100 \%=95,22 \%
\end{aligned}
$$

Untuk persentase secara keseluruhan dari aspek usability game edukasi matching Aksara Lampung memperoleh nilai $95,22 \%$.

\section{8) Pengujian Functionality}

Pada pengujian functionality, kuesioner diisi oleh orang yang memiliki keahlian dalam bidang softwareengineering untuk mengetahui apakah fungsi-fungsi pada game dapat berjalan dengan benar. Berikut hasil pengujian functionality, seperti ditunjukkan pada Tabel 8 .

\begin{tabular}{|c|c|c|c|}
\hline \multirow[b]{2}{*}{ No } & \multirow[b]{2}{*}{ Fungsi } & \multicolumn{2}{|c|}{ Hasil } \\
\hline & & Sukses & Gagal \\
\hline 1 & Menampillkan halaman Menu Utama. & 2 & 0 \\
\hline 2 & Memutar suara (backsolund dan sound effect) & 2 & o \\
\hline 3 & Tombol Home & 2 & 0 \\
\hline 4 & Tombol Mulai & 2 & o \\
\hline 5 & Tombol Tentang & 2 & 0 \\
\hline 6 & Tombol Petunjuk & 2 & o \\
\hline 7 & Tombol on ofof suara musik & 2 & 0 \\
\hline 8 & Tombol level mudah & 2 & o \\
\hline 9 & Tombol level sedang & 2 & o \\
\hline 10 & Tombol level sulit & 2 & 0 \\
\hline 11 & Tombol restart game & 2 & \\
\hline 12 & Tombol lanjut level berikutnya & 2 & o \\
\hline 13 & Tombol pilih level & 2 & 0 \\
\hline 14 & Tombol next & 2 & 0 \\
\hline 15 & Menampilkan halaman Tentang & 2 & o \\
\hline 16 & Menampilkan Halaman Petunjuk & 2 & 0 \\
\hline 17 & Mengakses halaman level mudah tingkat 1 & 2 & o \\
\hline 18 & Mengakses halaman level mudah tingkat 2 & 2 & 0 \\
\hline 19 & Mengakses halaman level mudah tingkat 3 & 2 & 0 \\
\hline 20 & Mengakses halaman level mudah tingkat 4 & 2 & 0 \\
\hline 21 & Mengakses halaman level mudah tingkat 5 & 2 & 0 \\
\hline 22 & Mengakses halaman level sedang tingkat 1 & 2 & 0 \\
\hline 23 & Mengakses halaman level sedang tingkat 2 & 2 & 0 \\
\hline 24 & Mengakses halaman level sedang tingkat 3 & 2 & 0 \\
\hline 25 & Mengakses halaman level sedang tingkat 4 & 2 & 0 \\
\hline 26 & Mengakses halaman level sedang tingkat 5 & 2 & 0 \\
\hline 27 & Mengakses halaman level sulit tingkat 1 & 2 & 0 \\
\hline 28 & Mengakses halaman level sulit tingkat 2 & 2 & 0 \\
\hline 29 & Mengakses halaman level sulit tingkat 3 & 2 & 0 \\
\hline 30 & Mengakses halaman level sulit tingkat 4 & 2 & 0 \\
\hline 31 & Mengakses halaman level sulit tingkat 5 & 2 & 0 \\
\hline & Total & 62 & 0 \\
\hline
\end{tabular}

TABEL 8

PENGUJIAN ASPEK FUNCTIONALITY

Selanjutnya dilakukan perhitungan persentase untuk pengujian aspek functionality yaitu sebagai berikut:

Persentase functionality = skor hasil pengujian $x 100 \%$

$$
=\frac{62}{62} \times 100 \%=100 \%
$$

Aspek functionalitygame edukasi Matching Aksara Lampung memperoleh nilai $100 \%$ dan artinya game dapat bekerja dengan baik dan benar.

\section{9) PengujianPortability}

Pengujian aspek Portability dilakukan dengan menjalankan aplikasi pada device (smartphone) sistem operasi Android, Kitkat, Lollipop, Marshmellodan Nougat.Berikut hasil pengujian portability, seperti ditunjukkan pada Tabel 9.

TABEL 9

TABEL PENGUJIAN ASPEK PORTABILITY

\begin{tabular}{|c|c|c|c|c|}
\hline No & Jenis Device & $\begin{array}{c}\text { Jenis } \\
\text { Android }\end{array}$ & $\begin{array}{c}\text { Proses } \\
\text { Instalasi }\end{array}$ & $\begin{array}{c}\text { Proses Runing } \\
\text { Aplikasi }\end{array}$ \\
\hline 1 & $\begin{array}{c}\text { Samsung Grand } \\
\text { Prime (layar 5 inci) }\end{array}$ & $\begin{array}{c}4.4 .4 \\
(\text { Kitkat })\end{array}$ & $\begin{array}{c}\text { Instalasi } \\
\text { Berhasil }\end{array}$ & $\begin{array}{c}\text { Berjalan baik } \\
\text { tanpa ada pesan } \\
\text { error }\end{array}$ \\
\hline 2 & $\begin{array}{c}\text { Xiaomi Redmi 3s } \\
\text { (layar 5 inci) }\end{array}$ & $\begin{array}{c}5.1 .1 \\
(\text { Lollipop })\end{array}$ & $\begin{array}{c}\text { Instalasi } \\
\text { Berhasil }\end{array}$ & $\begin{array}{c}\text { Berjalan baik } \\
\text { tanpa ada pesan } \\
\text { error }\end{array}$ \\
\hline 3 & $\begin{array}{c}\text { Alcatel Flashdua } \\
\text { (layar 5 inci) }\end{array}$ & $\begin{array}{c}6.0 .1 \\
(\text { Marshmello })\end{array}$ & $\begin{array}{c}\text { Instalasi } \\
\text { Berhasil }\end{array}$ & $\begin{array}{c}\text { Berjalan baik } \\
\text { tanpa ada pesan } \\
\text { error }\end{array}$ \\
\hline 4 & $\begin{array}{c}\text { Samsung Note 5 } \\
\text { (layar 5,7 inci) }\end{array}$ & $\begin{array}{c}7.0 .1 \\
\text { (Nougat) }\end{array}$ & Instalasi & $\begin{array}{c}\text { Berjalan baik } \\
\text { tanpa ada pesan } \\
\text { error }\end{array}$ \\
\hline
\end{tabular}


Pada pengujian Aspek Portability aplikasi game edukasi Matching Aksara Lampung, aplikasi dapat bekerja pada berbagai device dengan sistem operasi Kitkat, Lollipop, Marsmellodan Nougat.

\section{0) PengujianEfficiency}

Pengujian aspek efficiency menggunakan Page | 42 Testdroidsecara online.Dengan Testdroiddapat diamati penggunaan memory (RAM) dan CPU.Dalam pengujian Aspek efficiency ini dapat digunakan device yang sudah disediakan oleh Testdroidyaitu menggunakan device LG Google Nexus 5 6.0.1.Berikut ini hasil pengujian aspek efficiency dengan tools Testdroid:

1. Penggunaan memory oleh aplikasi ini tidak terlalu besar. Walaupun terdapat banyak gambar dan sound yang dimasukan pada aplikasi.

2. Penggunaan CPU maksimum berada di angka $44 \%$ saat awal masuk ke dalam game karena, CPU memproses data game seperti sound dan gambar. Sedangkan, rata-rata penggunaan $\mathrm{CPU}$ berada di angka 15\%. Angka tersebut masih berada di bawah batas aman yang ditetapkan oleh LittleEye (mobileappanalysistools).

\section{1) Analisis Hasil Pengujian}

Berdasarkan hasil dari pengujian yang dilakukan penulis yakni pengujian ISO 9126.Pengujian aspek usability diperoleh nilai untuk setiap kriteria di atas $81 \%$ yang artinya aspek usability dari aplikasi sudah "Sangat Layak".Pengguna dapat mengoperasikan aplikasi dengan mudah, pengguna memahami informasi dalam aplikasi dan pengguna tertarik dengan tampilan aplikasi. Secara keseluruhan persentase aspek usability 95,22\%. Pengujian functionality Aplikasi dapat melakukan 100\% fungsinya dengan benar. Pengujian Portability aplikasi dapat diinstall dan dijalankan pada device (smartphone) dengan sistem operasi Android Kitkat, Lollipop, Marshmellodan Nougat.Sehingga diperoleh persentase $100 \%$. Pengujian efficiency Tidak mengalami kekurangan memory yang menyebabkan terjadinya memory leak danmengakibatkan aplikasi berhenti padapenggunaan CPU.

\section{2) Analisis Minat Pengguna}

Observasi minat pengguna terhadap game edukasi matching Aksara Lampung yang dilakukan terhadap siswa Sekolah Dasar kelas 2 SDN 1 Tanjung Raya dan SDN 1 Tanjung Agung Bandarlampung. Berikut hasil pengujian minat pengguna terhadap game edukasi matching Aksara Lampung, seperti ditunjukkan pada Tabel 10.
TABEL 10

OBSERVASI MINAT PENGGUNA

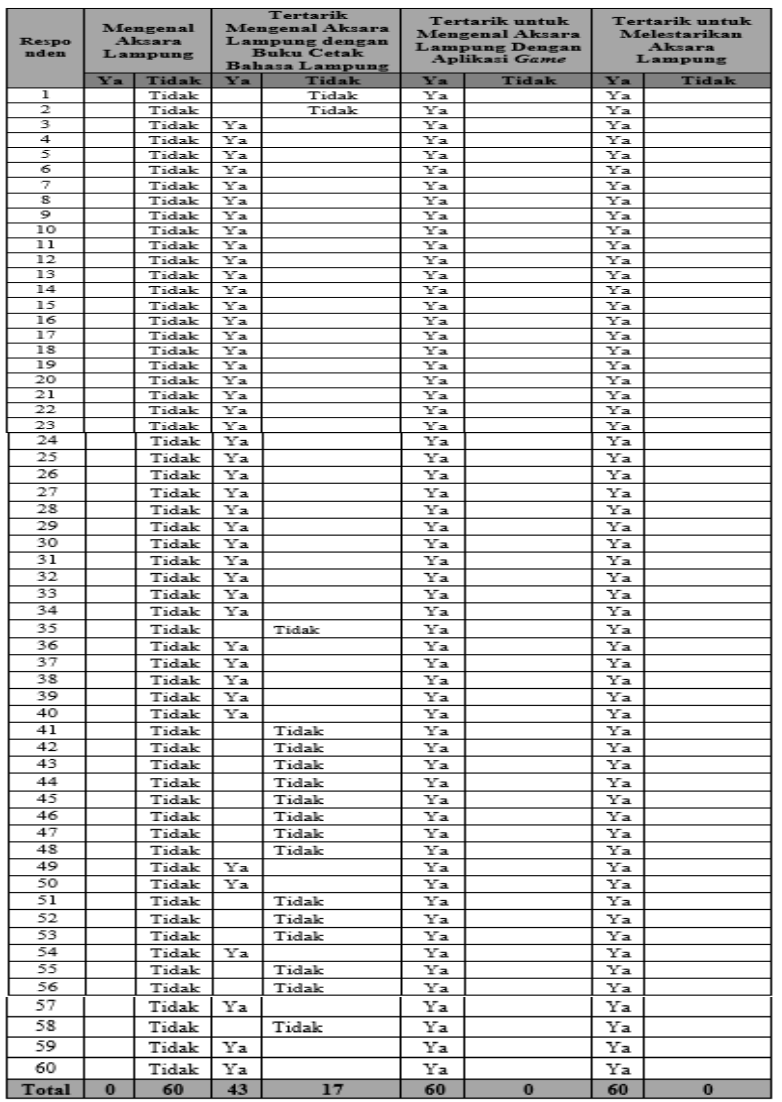

Berdasarkan observasi yang dilakukan dari 60 siswa SD kelas 2 sebanyak 60 siswa belum mengenal Aksara Lampung dalam hal ini belum mampu menulis, membaca maupun mengucapkan Aksara Lampung. Terdapat 43 siswa yang tertarik untuk membaca dan mengenal Aksara Lampung dengan buku cetak Bahasa Lampung (Dinas Pendidikan Provinsi Lampung). Sedangkan, untuk ketertarikan siswa mengenal dan mempelajari Aksara Lampung dengan media aplikasi game edukasi matching Aksara Lampung mencapai 60 siswa. Selanjutnya, ketika siswa diberi pertanyaan apakah tertarik untuk ikut mengenalkan dan melestarikan Aksara Lampung 60 siswa berpendapat tertarik.

Berikut grafik minat pengguna terhadap game edukasi matching Aksara Lampung, seperti ditunjukkan pada Gambar 8.

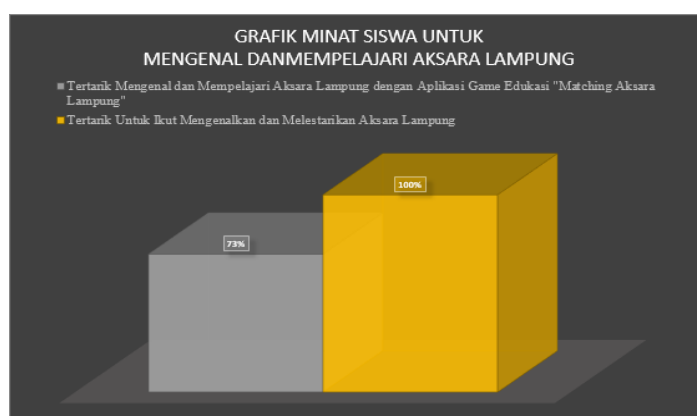

Gbr 8 Grafik Minat Pengguna 
Minat siswa untuk mengenal dan mempelajari Aksara Lampung saat diberikan buku konvensional, mencapai $73 \%$ (43 siswa) dari 60 siswa SD kelas 2. Sedangkan, setelah siswa menggunakan aplikasi game edukasi matching Aksara Lampung, minat siswa untuk mengenal dan mempelajari Aksara Lampung menggunakan aplikasi game mencapai angka 100\% (60 siswa). Dari hasil survei ini, berarti selisih perbandingan minat siswa mengalami peningkatan sebanyak $27 \%$.

\section{PENUTUP}

\section{A. Kesimpulan}

Berdasarkan hasil penelitian dan pembahasan dari hasil penelitian terhadap Game Edukasi Matching Aksara Lampung pada PlatformAndroid, maka dapat disimpulkan sebagai berikut:

1. Telah dibangun sebuah game edukasi matching Aksara Lampung, sebagai media pengenalan aksara Lampung yang yang dapat dioperasikan pada smartphone android. Perangkat android yang diuji untuk aplikasi game edukasi matching Aksara Lampung ini terdiri dari Kitkat, Lollipop,Marsmello dan Nougat $100 \%$ dapat beroperasi.

2. Aplikasi Game Edukasi Matching Aksara Lampung ini dibangun menggunakan game engine construct 2 . Tahapan yang digunakan pada pembuatan aplikasi game ini menggunakan tahapan pengembangan Multimedia Development Life Cycle yang terdiri dari concept, design, obtaining material collecting, assembly dan testing. Pengujian pada aplikasi game ini menggunakan ISO 9126 yang meliputi aspek functionality, usability, portabiity dan efficiency. Berikut hasil pengujianny kualitas game edukasi matching Aksara Lampung yaitu:

a. Hasil pengujian kualitas aspek functionality oleh 2 (dua) orang di bidang softwareengineering menunjukan bahwa aplikasi dapat melakukan $100 \%$ fungsinya dengan benar.

b. Hasil pengujian kualitas aspek portability pada beberapa device dengan sistem operasi Android versi Kitkat, Lollipop, Marshmallow dan Nouget menunjukkan aplikasi hanya dapat di-install dan dijalankan pada devicedengan versi android kitkatke atas, sehingga kualitas perangkat lunak dalam aspek portabilitymencapai $100 \%$.

c. Hasil pengujian kualitas aspek usability oleh 60 siswa kelas 2 SDN 1 Tanjung Agung, siswa kelas 3 SDN 1 Tanjung Raya, diperoleh nilai keseluruhan sebesar 95,22\% yang berarti aspek usability aplikasi ini sangat layak.

d. Hasil pengujian kualitas aspek efficiency dengan Testdroid menunjukkan tidak mengalami kekurangan memory yang menyebabkan terjadinya memory leak dan mengakibatkan aplikasi berhenti, penggunaan
CPU maksimum 44\% pada saat awal menjalankan aplikasi, rata-rata penggunaan CPU berada di angka $15 \%$.

3. Telah dibangun sebuah game edukasi untuk menarik minat anak sekolah dasar sebagai media pengenalan Aksara Lampung. Berdasarkan survei yang telah dilakukan terhadap 60 siswa yang terdiri dari siswa kelas 2 SD 1 Tanjung Raya dan SD 1 Tanjung Agung, $100 \%$ siswa belum mengenal Aksara Lampung, dan 100\% siswa tertarik untuk menggunakan aplikasi game edukasi matching Aksara Lampung ini sebagai media pengenalan Aksara Lampung.

\section{B. Saran}

Berdasarkan kesimpulan dari hasil penelitian yang telah diuraikan, maka saran yang dapat diberikan untuk peneliti selanjutnya terhadap Game Edukasi Matching Aksara Lampung pada PlatformAndroid yaitu:

1. Aplikasi ini dapat dikembangkan dengan menambah konten penggabungan induk huruf dan anak huruf dan bahasa Lampung serta menambahkan animasi pada setiap gambar ilustrasi aksara.

2. Aplikasi ini dapat dikembangkan dengan menambahkan tingkatan pada setaip level game edukasi lainnya.

3. Menggunakan alternatif game engine lainnya, sehingga besar penggunaan CPU pada awal aplikasi dijalankan dapat minimalkan.

\section{REFERENSI}

[1] Aryantio, A. \&Munir, R., 2015, Pengenalan Aksara Lampung Menggunakan Jaringan Syaraf Tiruan, Makalah KNIF, 34-38.

[2] Kleden, M. A., Lobo, M. \& Ndii, M. Z., 2016, Analisis Pengaruh Penggunaan Smartphone/Handphone Terhadap Prestasi Belajar Mahasiswa, Jurusan Matematika FST, Undana.

[3] Safaat \& Nazaruddin., 2013, Aplikasi Berbasis Android Berbagai Implementasi dan Pengembangan Aplikasi Mobile Berbasis Android, Informatika, Bandung.

[4] Ayu, S.F., Sutardi. \& Tajidun, LM., 2017, Rancang Bangun Game Edukasi Puzzle Kebudayaan Sulawesi Tenggara Dengan Algoritma Fisher-Yates Suffle, Jurusan Teknik Informatika, Universitas Halu Oleo, Kendari.

[5] Yuliana, E., 2013, Perancangan Aplikasi Multimedia Pembelajaran Bahasa Dan Aksara Lampung Menggunakan Adobe Flash, AMIKOM Yogyakarta, Yogyakarta.

[6] Noeh, M. \& Harisfadilah., 1979, Kamus Umum Bahasa Lampung Indonesia, Universitas Bandarlampung, Bandarlampung.

[7] Wulandari, A.D., 2012, Game Edukatif Sejarah Komputer Menggunakan Role Playing Game (RPG) Maker XP Sebagai Media Pembelajaran di SMP Negeri 2 Kalibawang, Fakultas Teknik, Universitas Negeri Yogyakarta.

[8] Egenfeldt, N.S., 2015, Making Sweet Music: The Educational Use of Computer Games, Url: http://www.egenfeldt .eu/papers/sweet_music.pdf.

[9] Susilana, R. \& Riyana, C., 2009, Media Pembelajaran Hakikat, Pengembangan, Pemanfaatan dan Penilaian, Bandung. 
CESS (Journal of Computer Engineering System and Science)

Vol. 3 No. 1 Januari 2018

[10] Dillon, R., 2014, HTML5 Game Development from the Ground Up with Construct 2, Boca Raton, Taylor \& Francis Group.

[11] Rosa, A. S. \& Shalahudin, M., 2013, Rekayasa Perangkat Lunak (Terstruktur dan Berorientasi Objek), Informatika, Bandung.

[12] Herman. \& Is, M., 2009, Buku Pelajaran Bahasa Lampung..
p-ISSN :2502-7131

e-ISSN :2502-714x

Page | 44 